\title{
Sustainability spillover effects and partnership between East Asia \& Pacific versus North America: interactions of social, environment and economy
}

\author{
Mehrab Nodehi ${ }^{1} \cdot$ Abbas Assari Arani $^{2} \cdot$ Vahid Mohamad Taghvaee ${ }^{2}$ (D)
}

Received: 13 April 2021 / Accepted: 27 September 2021 / Published online: 23 October 2021

(c) The Author(s), under exclusive licence to Springer-Verlag GmbH Germany, part of Springer Nature 2021

\begin{abstract}
The three sustainability pillars of social, environment and economy were initially introduced by the United Nations in 2002, addressing major global sustainability issues including economic problems, income inequality, environmental pollution and social shortcomings. Comparing East Asia \& Pacific with North America, there is a growing concern over economic, political and even social competition as a result of recent development and industrialization that is taking place in Asian countries. This might lead to an unhealthy conflict that favors regional independency as opposed to the current globalization and trade facilitation trend. As a result, this study aims to assess the effects of development in three main pillars of sustainability (social, environment and economy) in the East Asia and Pacific on that of North America and vice versa. To estimate this interactive or spillover effects of sustainable development (or sustainability elasticities), our research employs Econometric methodologies including Simultaneous Equations System, Vector AutoRegressive (VAR) and Granger Causality approaches during 1971-2016. The results show that most of the sustainability elasticities are positive between and inside the two regions, supporting the synergetic character of the sustainability spillover effects and confirming constructive role of globalization and openness in the sustainability progress. Based on the results, this research suggests policy-makers to follow cooperative and flow-based governance rather than the placed-based or regional independent thinking that supports integrated sustainable development benefiting not only the two parties but also the overall global sustainability.
\end{abstract}

Keywords Sustainability - Sustainable development - Spillover effect · Partnership · Peace $\cdot$ Globalization · Openness

JEL Code $\mathrm{O} 19 \cdot \mathrm{O} 24 \cdot \mathrm{O} 21 \cdot \mathrm{Q} 52 \cdot \mathrm{Q} 56$

Vahid Mohamad Taghvaee

V.Taghvaee@modares.ac.ir

Extended author information available on the last page of the article 


\section{Introduction}

The three pillars of sustainability, initially introduced by the United Nations in 2002 and 2015, respectively, are a comprehensive united manifesto to address the major global sustainability issues including economic problems, income inequality, environmental pollution and social concerns (Allen et al. 2019; Fullman et al. 2017; Hák et al. 2016; Lyytimäki et al. 2020; Nilsson et al. 2016; Nodehi and Taghvaee 2021a; Smith et al. 2018; Taghvaee et al. 2021). The development of such goals is a response to polarization of different regions in the world, often sharing the same issues such as the ever-increasing population, environmental degradation and social issues (Liu et al. 2020).

Depending on the global regions, the condition, development, and issues might vary, yet, in all forms, both the industrialized and un-industrialized regions often experience the same issues such as poverty, social issues and environmental pollution. As such, around $23 \%$ of the world mortalities are from the environmental issues (annually 12.6 million deaths) with Asia having the highest reported cases (WHO 2018). In the same way, the top 8 greenhouse gas emitters in 2019 are China, US, Japan, South Korea, Iran, Saudi Arabia, and Canada, located either in Asia \& Pacific or in North America (Amin et al. 2020). With both of the continents are competing for economic growth in two distinctive polarization of East and West (especially referring to China and US trade conflict), environmental degradations and economic and trade conflicts are emerging as its result (Xiong and $\mathrm{Wu}$ 2021). In this environment, the economic competition between the two regions is likely to exacerbate the environmental pollution and trade obstacles, affecting the global sustainability and the sustainable development goals. These issues are observable in the emergence of growing political conflicts over trade tariffs and market competition in the recent years (Liu et al. 2020). These conflicts inspire the governments to pursue place-based policies with domestic and independent outlook rather than flow-based ones with global perspectives.

To assess this issue, our study aims to evaluate the effects of globalization and openness on sustainable development in the North America versus that of East Asia and Pacific. To do so, this study tries to map the spillover (or interactive) effects, considered as a proxy for globalization and openness, between the two regions. With spillover effect referring to the impact of seemingly unrelated events to a variable (Liu et al. 2018; Sadorsky 2014), a positive (or negative) spillover effect imply synergistic (or trade-off) relationships and beneficial (or detrimental) role of globalization and openness in the sustainability of the two regions, implicitly. This analysis is helpful for policy-makers to develop flow-based (or place-based) governance in case of synergistic (or trade-off) relationship. Synergistic (or trade-off) spillover effects are an evidence for the beneficial (or detrimental) role of globalization and openness in the sustainability of the two competing regions. 


\section{Global sustainability and spillover effects}

Global sustainability refers to the interactions among humans, societies, and the biosphere on global scale that co-exist and function in harmony to enable productive growth, stability and resilience for current and future generations (Brown et al. 1987). In its essence, global sustainability considers an inter-related chain of variables that incorporates socio-economic and environmental interactions to potentially create sustainability solutions (Batabyal and Folmer 2020; Hull and Liu 2018; Liu et al. 2015; Nodehi and Taghvaee 2021b). This, in effect, requires a deeper understanding of interconnected effects of such variables (or spillover effects), that evaluates the effect of a given factor in a flow-based system, as opposed to the most commonly considered holistic approaches. Being rooted in the externalities of processes or activities (Uyar et al. 2021), previous studies have shown the effect of geographical vicinity of different countries on public and non-public sectors (Wang and Wu 2016). In this regard, regional proximity and geographical connectivity have relational effects on the productivity generating synergic effects on other economies which is commonly referred to as 'spatial diffusion with friction' (Geoffrey 2007).

Yet, recent mainstream contributions of growth in literature have shown that such interrelation is heterogeneous across regions or major economies (Basile et al. 2011) and can potentially spill over with different intensities according to geographical distance (spatial friction hypothesis). Such non-linearity (spatial heterogeneity), in effect, can be an indication of global spillover effect from region-to-region and localto-local scales (Basile 2008; Batabyal and Nijkamp 2017). This, in other words, considers the regional spillover effects to be an inter-dependent component of its origin, local-to-local spillover, and its respective intensity (Basile et al. 2011) With such basis, exogenous variables such as the 3 commonly-known pillars of sustainability (economy, environment and social) (Taghvaee, Arani, Nodehi, et al. 2021), provide an insight on the degree of intensity for spillover effects on different regions (in this study, East Asia \& Pacific versus North America). Despite various interpretation of the spillover results in different fields and sectors, it generates the need for specific policy interventions of countries located in the two mentioned competing-regions.

\section{Methodology}

To estimate the sustainable development spillover effects (or sustainability elasticities) between East Asia \& Pacific versus that of North America, this research develops SEY ${ }^{1}$ model following (Taghvaee et al. 2021) as a package of Simultaneous Equations System, Vector AutoRegressive (VAR) and Granger Causality approaches during 1971-2016.

\footnotetext{
${ }^{1}$ SEY model stands for Social (S), Environment (E), and Economy (Y) which are the three pillars of sustainability.
} 
According to the assumption of SEY model, development in each sustainability pillar in region " $\mathrm{i}$ " is a function of development in the sustainability pillars of region "j", as in Eq. 1 (Mirshojaeian Hosseini and Kaneko 2012).

$$
\begin{aligned}
& S_{i}=f\left(S_{j}, E_{j}, Y_{j}\right) \\
& E_{i}=f\left(S_{j}, E_{j}, Y_{j}\right) \\
& Y_{i}=f\left(S_{j}, E_{j}, Y_{j}\right)
\end{aligned}
$$

where S, E and Y are social, environment and economy pillars of sustainability, respectively. "i" and "j" are East Asia \& Pacific and North America.

The SEY model is transformed into Simultaneous Equation System, as follows (Abdouli and Omri 2020; Ben Youssef et al. 2016; Kahouli and Omri 2017; Taghavee et al. 2016).

$$
\begin{aligned}
L E_{i t} & =\alpha_{0 j}+\alpha_{1 j} L E_{j t}+\alpha_{2 j} C O_{j t}^{-1}+\alpha_{3 j} G D P_{j t}+\varepsilon_{1 t} \\
C O_{i t}^{-1} & =\beta_{0 j}+\beta_{1 j} L E_{j t}+\beta_{2 j} C O_{j t}^{-1}+\beta_{3 j} G D P_{j t}+\varepsilon_{2 t} \\
G D P_{i t} & =\theta_{0 j}+\theta_{1 j} L E_{j t}+\theta_{2 j} C O_{j t}^{-1}+\theta_{3 j} G D P_{j t}+\varepsilon_{3 t}
\end{aligned}
$$

where LE is life expectancy measured in year as an index for social pillar of sustainability; $\mathrm{CO}^{-1}$ is the inverse of $\mathrm{CO}_{2}$ emissions per capita in $1 /$ metric tons as a proxy for environmental pillar of sustainability; GDP is Gross Domestic Production per capita in constant 2010 US Dollar as a proxy for economic pillar of sustainability; $\alpha_{0}, \beta_{0}$ and $\theta_{0}$ are intercept; $\varepsilon$ is error terms; and $\mathrm{t}$ is year.

These simultaneous equations systems, for estimating the coefficients, employ two approaches.

- Limited Information Approach is for estimating the equations one by one as a single regression. This approach covers four distinctive methods: Ordinary Least Squares (OLS); Weighted Ordinary Least Squares (WOLS); 2-Step Least Squares (2SLS); and Weighted 2-Step Least Squares (WSLS).

- Full Information Approach is for estimating the equations altogether. This approach is in four methods: 3-Step Least Squares (3SLS); Seemingly Unrelated Regressions (SUR); Generalized Methods of Moments (GMM); and Full Information Maximum Likelihood (FIML).

The coefficients are the sustainability elasticities (Taghvaee et al., 2019). Since all the variables are in natural logarithm form, $\alpha, \beta$ and $\theta$ are the spillover elasticities of social, environmental and economic sustainability. $\alpha_{1}, \alpha_{2}$ and $\alpha_{3}$ are the social, environment and economy spillover elasticity of social sustainability; $\beta_{1}, \beta_{2}$ and $\beta_{3}$ are those of the environment sustainability; and $\theta_{1}, \theta_{2}$ and $\theta_{3}$ are those of the economic sustainability, respectively.

To unify the resulted elasticities of various methods, this research calculates the arithmetic mean of elasticities resulted from the different methods.

Since the elasticities are comparable with one another, this study calculates their arithmetic mean to give unique elasticity for sustainability as follows. 
$\left(\alpha_{1}+\beta_{1}+\theta_{1}\right) / 3 \leftrightarrow$ Social spillover - elasticities of sustainability.

$\left(\alpha_{2}+\beta_{2}+\theta_{2}\right) / 3 \leftrightarrow$ Environment spillover - elasticities of sustainability.

$\left(\alpha_{3}+\beta_{3}+\theta_{3}\right) / 3 \leftrightarrow$ Economic spillover - elasticities of sustainability.

$\left(\alpha_{1}+\alpha_{2}+\alpha_{3}\right) / 3 \leftrightarrow$ Spillover - elasticities of social sustainability.

$\left(\beta_{1}+\beta_{2}+\beta_{3}\right) / 3 \leftrightarrow$ Spillover - elasticities of environmental sustainability.

$\left(\theta_{1}+\theta_{2}+\theta_{3}\right) / 3 \leftrightarrow$ Spillover - elasticities of economic sustainability.

$\sum_{k=1}^{3}\left(\alpha_{k j}+\beta_{k j}+\theta_{k j}\right) / 9 \leftrightarrow$ Spillover - elasticities of sustainability for region $\mathrm{j}$.

Only those elasticities are considered in our analysis about the sustainability which show causal relationships, estimated with VAR and Granger causality approach as follows (Boutabba and Ahmad 2017; Ismael et al. 2018; Mamipour et al. 2019; Tan and Lu 2015)

$$
\begin{aligned}
& \Delta L E_{i t}=C_{t}+\sum_{l=1}^{p} \alpha_{1 l} \Delta L E_{j t-l}+\sum_{l=1}^{p} \alpha_{2 l} \Delta C O_{j t}^{-1}+\sum_{l=1}^{p} \alpha_{3 l} \Delta G D P_{j t}+\varepsilon_{1 t} \\
& \Delta C O_{i t}^{-1}=C_{t}+\sum_{l=1}^{p} \beta_{1 l} \Delta L E_{j t-l}+\sum_{l=1}^{p} \beta_{2 l} \Delta C O_{j t}^{-1}+\sum_{l=1}^{p} \beta_{3 l} \Delta G D P_{j t}+\varepsilon_{1 t} \\
& \Delta G D P_{i t}=C_{t}+\sum_{l=1}^{p} \theta_{1 l} \Delta L E_{j t-l}+\sum_{l=1}^{p} \theta_{2 l} \Delta C O_{j t}^{-1}+\sum_{l=1}^{p} \theta_{3 l} \Delta G D P_{j t}+\varepsilon_{1 t}
\end{aligned}
$$

where 1 is lag and $p$ is the optimal lag. It gives impulse response functions, showing how each pillar of sustainability in region "i" responses to the changesssss in sustainability pillars in region "j".

Finally, this research considers only those coefficients which not only are statistically significant in the simultaneous equations system, but also reveals significant causal relationship in the Granger Causality and VAR approach. The arithmetic average of the elasticities are the sustainability elasticities.

The SEY model employs simultaneous equations system, Granger causality and VAR approaches to estimate the sustainability elasticities and spatial spillover effects. The positive coefficients imply the synergistic nature of sustainability spillover effects between the two regions of North America and East Asia, while the negative coefficients confirm the trade-off nexus (Štreimikiene and Kačerauskas 2020; Tremblay et al. 2020; Umar et al. 2020; Xu et al. 2020). The 
synergistic and trade-off relationships suggest that the effects of globalization and openness are beneficial for or detrimental to the sustainability, respectively.

In addition to the cross-region estimations, this study investigates the interactions of the sustainable development pillars inside each region separately. This shows how development of each pillar in each region affect the development of other pillars in the same region.

To show the reliability of the results, this research goes further to estimate all the above models and equations with alternative proxies and variables for the three pillars of sustainable development. In the second round of estimations, this study considers school enrolment primary ( $\%$ gross) ${ }^{2}$ inverse of greenhouse gas emissions (in kilo of $\mathrm{CO}_{2}$ equivalent per capita) and energy use (in $\mathrm{kg}$ of oil equivalent per capita) as proxies for the social, environmental and economic pillars of sustainable development. In the equations and models, their symbols are $\mathrm{SC}, \mathrm{GH}^{-1}$ and $\mathrm{EN}$, respectively.

All the data are extracted from the World Development Indicators, World Bank, within 1971-2016; and for the alternative variables, the period is 1971-2014 (World Bank, 2021). They are normalized values of the natural logarithm form. ${ }^{3}$

The data are accessible at the following link (Nodehi et al. 2021).

https://data.mendeley.com/datasets/xvd7bv6mjb/5

\section{Result}

The results show that most of the sustainability elasticities are positive both between and within East Asia \& Pacific and North America, supporting the synergetic character of the sustainability spillover effects.

Table A-1 to Table A-6 in the Appendix, and Figure A-1 and Figure A-2 show the results of simultaneous equations system, Granger causality and VAR approaches. According to Table A-1 to Table A-6 in the Appendix, the signs are positive for most of the elasticities with statistically significant causal and long-run relationship, supporting the synergetic character of sustainability spillover effects both between and within North America and Asia even with changing the proxies. Although, this research employs various methods to estimate the SEY model including limited information (OLS, WOLS, 2SLS and WSLS) and full information (3SLS, SUR, GMM and FIML), all the methods give the same results. It shows that the results are valid and robust. In the appendix, Figure A-1 and Figure A-2 present the impulse functions of the SEY model. These tables and figures show that the relationship

\footnotetext{
2 "Gross enrollment ratio is the ratio of total enrollment, regardless of age, to the population of the age group that officially corresponds to the level of education shown. Primary education provides children with basic reading, writing, and mathematics skills along with an elementary understanding of such subjects as history, geography, natural science, social science, art, and music." (World Bank, 2021).

3 The normalization is according to the following equation:

Normalizedvalue $=\frac{\text { Currentvalue-Maximumvalue }}{\text { Maximumvalue-Minimumvalue }}$

After normalization, all the variables are put into unit root tests and they are stationary in level, paving the way to run the model without any worry for spurious regression result.
} 
Table 1 Interactive sustainability elasticities between North America and East Asia \& Pacific (with the 1st set of proxies: Life expectancy, $\mathrm{CO}_{2}$ and GDP)

\begin{tabular}{llll}
\hline Region $\mathrm{j}=>$ Region $\mathrm{j}$ & & Asia $=>$ America & America $=>$ Asia \\
\hline Social $_{j}$ & & & \\
Social $_{\mathrm{j}}$ & $L E_{j} \Rightarrow L E_{j}$ & $+1.0718^{* * *}$ & $+0.5782^{* * *}$ \\
Environment $_{\mathrm{j}}$ & $C O_{j}^{-1} \Rightarrow L E_{j}$ & - & - \\
Economy $_{\mathrm{j}}$ & $G D P_{j} \Rightarrow L E_{j}$ & - & - \\
Environment $_{i}$ & & & - \\
Social $_{\mathrm{j}}$ & $L E_{j} \Rightarrow C O_{j}^{-1}$ & - & - \\
Environment $_{\mathrm{j}}$ & $C O_{j}^{-1} \Rightarrow C O_{j}^{-1}$ & - & - \\
Economy $_{\mathrm{j}}$ & $G D P_{j} \Rightarrow C O_{j}^{-1}$ & $+0.4588^{* * *}$ & $-0.2459^{* * *}$ \\
Economy $_{j}$ & & & - \\
Social $_{\mathrm{j}}$ & $L E_{j} \Rightarrow G D P_{j}$ & $+0.2873^{* * *}$ & - \\
Environment $_{\mathrm{j}}$ & $C O_{j}^{-1} \Rightarrow G D P_{j}$ & - & $+17 \% * * *$ \\
Economy $_{\mathrm{j}}$ & $G D P_{j} \Rightarrow G D P_{j}$ & $+0.7811^{* * *}$ & \\
Interactive Sustainability Elasticities & $+64 \%$ & \\
\hline
\end{tabular}

among the sustainable development pillars are significant with various methods, proxies, variables and regions. It is an evidence for the existence of positive sustainable development spillover effects among the regions.

Table 1 presents only those coefficients of the Table A-1, Table A-2 in the Appendix and Figure A-1 which are statistically significant both in the simultaneous equations systems and in the Granger Causality tests. These are actually the elasticities of sustainable development pillars in East Asia \& Pacific and North America. The social development in each region has the most considerable spillover effect on the social development in the other region. This effect is about +107\% from Asia to America and 57\% from America to Asia. Although, the social development in Asia has positive effect on the economic development in America (about $+28 \%$ ), the social development in America has negative effect on economic development in Asia (about - 24\%). In addition, the economic development in Asia has spillover effects on both the economic and the environmental development in America, approximately $+78 \%$ and $+45 \%$ respectively. At the final row of Table 1, the interactive sustainability elasticities are the average the elasticities in the table, showing that sustainability in North America improves 64\%, if sustainability in East Asia \& Pacific improves $100 \%$. Likewise, sustainability in East Asia \& Pacific increases $17 \%$, in case of $100 \%$ improvement in the sustainability of North America. Therefore, the spillover effects of sustainability are positive and synergistic between North America and East Asia.

In addition to the cross-region estimations, this research estimates the spillover effects of sustainable development pillars inside each region, summarized in Table 2 (also see Table A-3 and Table A-4 in the Appendix). This estimation also shows that the spillover effects of sustainability are significantly and mostly positive in a single region. Table 2 presents only those coefficients of the Table A-3, Table A-4 and Figure A-2 in the appendix which are statistically significant both in the simultaneous 
Table 2 Interactive sustainability elasticities within North America and East Asia \& Pacific (considering the interactions of each region separately) using the 1st set of proxies: Life expectancy, $\mathrm{CO}_{2}$ and GDP)

\begin{tabular}{llll}
\hline Region $\mathrm{j}=>$ Region $\mathrm{j}$ & Asia $=>$ Asia & America $=>$ America \\
\hline Social $_{j}$ & $L E_{j} \Rightarrow L E_{j}$ & - & - \\
Social $_{\mathrm{j}}$ & $C O_{j}^{-1} \Rightarrow L E_{j}$ & - & - \\
Environment $_{\mathrm{j}}$ & $G D P_{j} \Rightarrow L E_{j}$ & - & - \\
Economy $_{\mathrm{j}}$ & & & - \\
Environment $_{i}$ & $L E_{j} \Rightarrow C O_{j}^{-1}$ & - & - \\
Social $_{\mathrm{j}}$ & $C O_{j}^{-1} \Rightarrow C O_{j}^{-1}$ & - & - \\
Environment $_{\mathrm{j}}$ & $G D P_{j} \Rightarrow C O_{j}^{-1}$ & - & $+0.5680^{* * *}$ \\
Economy $_{\mathrm{j}}$ & & & - \\
Economy $_{j}$ & $L E_{j} \Rightarrow G D P_{j}$ & $+0.5147^{* * *}$ & - \\
Social $_{\mathrm{j}}$ & $C O_{j}^{-1} \Rightarrow G D P_{j}$ & $-0.0180^{* * *}$ & $+70 \%$ \\
Environment $_{\mathrm{j}}$ & $G D P_{j} \Rightarrow G D P_{j}$ & - & \\
Economy $_{\mathrm{j}}$ & Interactive Sustainability Elasticities & $+25 \%$ & \\
\hline
\end{tabular}

Table 3 Interactive sustainability elasticities between North America and East Asia \& Pacific (with the $2^{\text {nd }}$ set of proxies: School enrolment, Greenhouse gas emissions and Energy consumption)

\begin{tabular}{|c|c|c|c|}
\hline \multicolumn{2}{|c|}{ Region $\mathrm{j}=>$ Region $\mathrm{i}$} & \multirow[t]{2}{*}{ Asia $=>$ America } & \multirow[t]{2}{*}{ America $=>$ Asia } \\
\hline Social $_{i}$ & & & \\
\hline Social $_{j}$ & $S C_{j} \Rightarrow S C_{i}$ & - & $+0.6836 * * *$ \\
\hline Environment $_{\mathrm{j}}$ & $G H_{j}^{-1} \Rightarrow S C_{i}$ & - & - \\
\hline Economy $_{\mathrm{j}}$ & $E N_{j} \Rightarrow S C_{i}$ & - & - \\
\hline \multicolumn{4}{|l|}{ Environment $_{i}$} \\
\hline Social $_{j}$ & $S C_{j} \Rightarrow G H_{i}^{-1}$ & $+1.4525^{* * *}$ & - \\
\hline Environment $_{\mathrm{j}}$ & $G H_{j}^{-1} \Rightarrow G H_{i}^{-1}$ & - & $-0.1264 * * *$ \\
\hline Economy $_{\mathrm{j}}$ & $E N_{j} \Rightarrow G H_{i}^{-1}$ & - & - \\
\hline \multicolumn{4}{|l|}{ Economy $_{i}$} \\
\hline Social $_{j}$ & $S C_{j} \Rightarrow E N_{i}$ & $-0.3893 * * *$ & - \\
\hline Environment $_{\mathrm{j}}$ & $G H_{j}^{-1} \Rightarrow E N_{i}$ & - & $0.1688 * * *$ \\
\hline Economy $_{\mathrm{j}}$ & $E N_{j} \Rightarrow E N_{i}$ & - & - \\
\hline \multicolumn{2}{|c|}{ Interactive Sustainability Elasticities } & $+53 \%$ & $+24 \% * * *$ \\
\hline
\end{tabular}

equations systems and in the Granger Causality tests. According to the tables, the majority of the resulted coefficients are positive. It confirms the coefficients of the estimated models which are in Table 1, Table A-1, and Table A-2. Thus, this is also an evidence which supports the positive nature of sustainability spillover effects.

To show the robustness of the results, this study replicates all the estimated models with another set of proxies for the pillars of sustainable development, summarized in Table 3 (also see Table A-5 and Table A-6 in the Appendix). The spillover effects of sustainable development show positive and synergetic nature even in case 
of changing the proxies. It is also another evidence for the reliability of the model estimations in this research. Based on these results, the nature of the sustainable development pillars is positive and synergetic even in case of altering the variable sets and region interactions.

This research employs various methodologies, models, proxies, variables and regions to enhance the reliability of its results. This study estimates the spillover effects of sustainable development pillars not only between the two regions but also inside each region to show the reliability of the results. Again, for more reliability, this study goes further to estimate the models with another set of proxies to check the findings with alternative variables and proxies. Although, it is possible to employ more and more proxies, variables, models and regions to estimate the spillover effects, space and word limits are a restriction to do all of them in only one single paper. Hence, we leave this task for the future studies. Additionally, each study is to answer its question/s with a limited number of models and variables; and no study has the capacity to cover all the available variables, proxies and models in only one single research. Regarding this analysis, our study supports the synergetic characteristics of sustainable development pillars on the basis of its own estimated models, datasets and proxies which are undoubtedly limited just like all the other studies with their limited models, variables and estimations.

Tables 3, 4 and 5 are a very brief summary of all the 6 tables and 2 figures in the appendix (Table A-1 to A-6 and Figure A-1 and A-2). As a summary, Tables 3, 4 and 5 represent the statistically significant causalities with average long-run relationships of sustainable development pillars between and within North America and East Asia \& Pacific, considering two sets of proxies. Numbers are the sustainability elasticities (or rather the spillover effects of sustainable development pillars) as the positive ones are synergies and the negative one is trade-off nexus. The average of the averages is the interactive sustainability elasticity.

\section{Discussion}

Findings of this research support the positive role of globalization and openness in the global sustainability. Figure 1 is the graphical translation of Table 1, showing the supporting role of globalization and openness in sustainability of East Asia \& Pacific and North America. According to Fig. 1, except one trade-off nexus (- 24\%), all the bilateral relationships between the two regions are synergetic (or positive), specifically for the social and economic interactions. Thus, according to the results, the sustainability spillover effects are positive, confirming constructive role of globalization and openness in the sustainability progress.

These positive relationships are observable not only in this model but also, in the other alternative models. In addition to the cross-region analysis, our findings confirm that these synergetic relationships exist among the sustainability pillars inside each single region, as shown in Fig. 2. Accordingly, this research claims that such synergetic nexus is noticeable even if the variables and proxies change totally, as shown in Fig. 3. Regarding Fig. 3, most of the spillover effects are positive. Despite some minor negative and trade-off spillover effects, the major interactions are 
positive and synergetic. Therefore, the synergetic nexus of sustainability pillars is considerable in various regions, models, proxies and variables.

The considerable influence of spillover effects on sustainability nominates it as the $4^{\text {th }}$ pillar of sustainable development alongside with social, environment and economy to introduce a new sustainability perspective, i.e., Integrated Sustainability. In contrast with the weak sustainability perspective that values all the sustainable development pillars equally and the strong sustainability that considers environment more important than the other pillars, our newly-defined perspective, Integrated Sustainability, considers spillover effect as the most dominant pillar of sustainable development. Through the Integrated Sustainability and its spatial synergies, therefore, the globalization and openness are beneficial for sustainable development in the two regions.

\section{China as an emerging superpower}

The growing concern over unhealthy competition between East Asia versus that of North America is the result of the power transition that has taken place in recent decades, challenging the contemporary global socio-economic stance. In East Asia and Pacific, China, with a population of around 1.4 billion and a GDP of 14.72 trillion (World Bank Group 2021), is a de facto superpower and the major dominating country with the most significant impact on the three pillars of social, economic and environment of the entire region. On this basis, China has become a major rival to the United States whose global dominance has been unchallenged, after the fall of the Soviet Union, for decades. Although the two dominating forces have a considerably different socio-economic stance (e.g., Liberalism versus Socialism), their impact on the regional and global spillover sustainability is equally significant. This, in sustainability terminology, is referred to the effects of synergetic or trade off relationships, resulting in flow-based (and cooperative) or place-based (and independent) governance, respectively.

Effectively, based on the result of this study, despite the variation in the benefits of partnership between the two major superpowers that can have more benefits for one over the other, both parties are found to be positively influenced from collaboration rather than an unhealthy conflicting competition. Yet, the degree to which, such benefits can exist is in direct relationship to the two parties' willingness to adopt cooperative policies that enhance the social, environment and economic sustainability, not only on regional but also on a global scale.

\section{Conclusion}

This study investigates the spatial spillover effects between North America and East Asia \& Pacific to find whether or not globalization and openness are beneficial for the global sustainability. As a result of this research, the regional spillover effects of sustainability are found to be dominantly positive both between and within East Asia \& Pacific and North America, showing the beneficial effects of globalization 


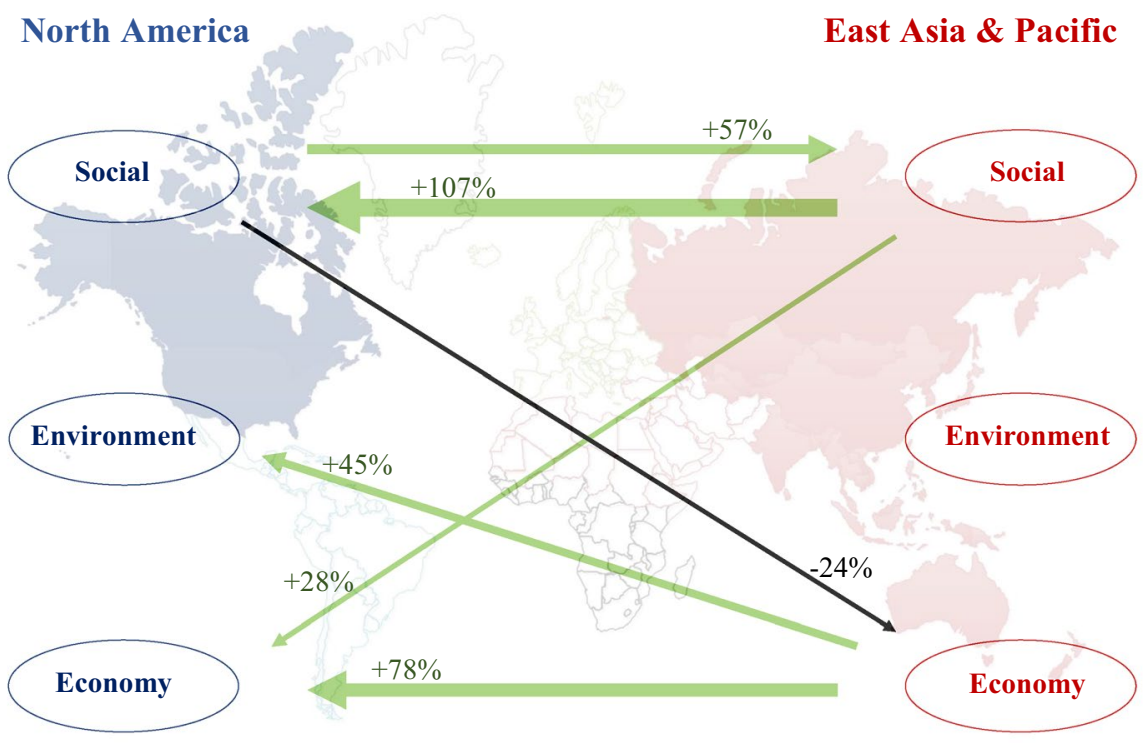

Fig. 1 Estimated spillover effects (or elasticities) of sustainable development pillars between East Asia \& Pacific and North America (with 1st set of proxies: Life expectancy, $\mathrm{CO}_{2}$ and GDP)

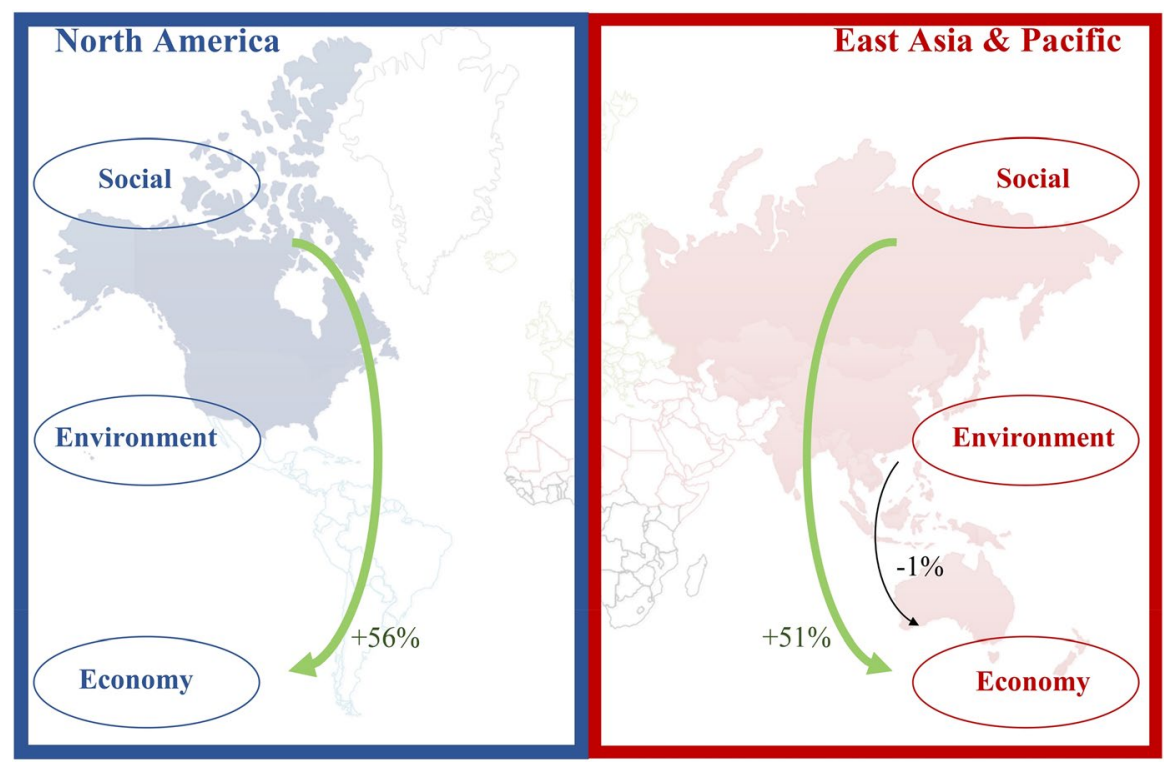

Fig. 2 Estimated spillover effects (or elasticities) of sustainable development pillars within East Asia \& Pacific and North America (considering the interactions of each region separately) 


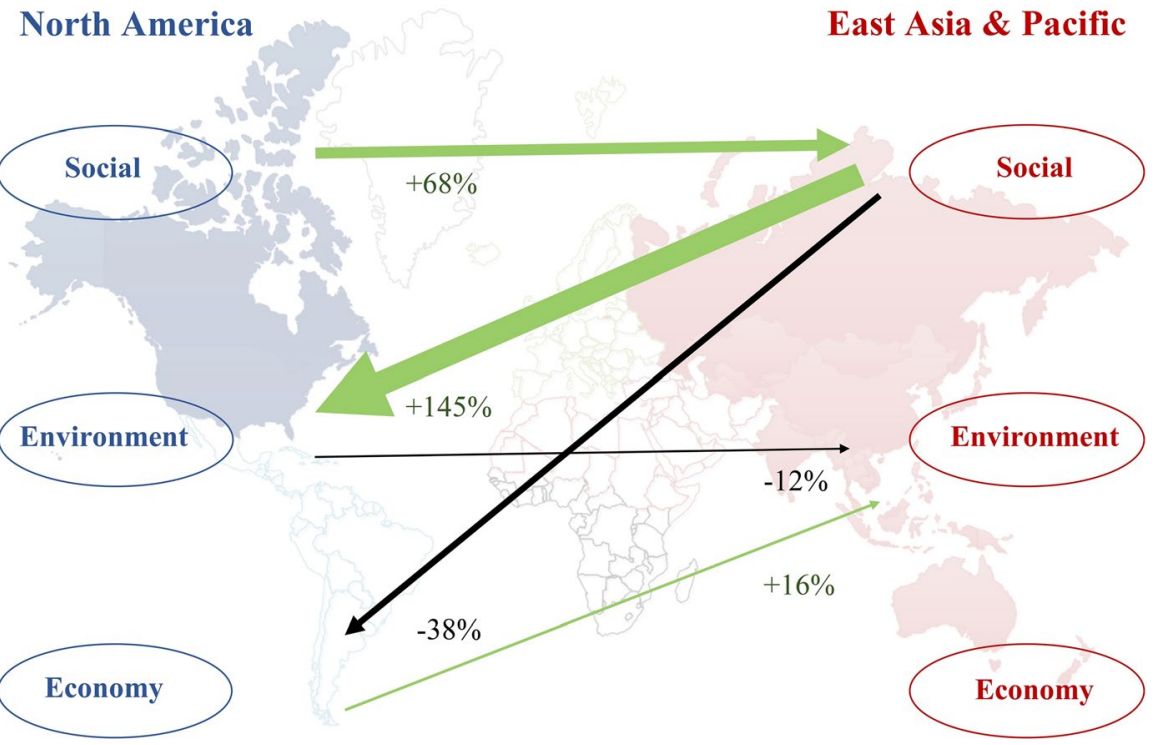

Fig. 3 Estimated spillover effects (or elasticities) of sustainable development pillars between East Asia \& Pacific and North America (with the 2nd set of proxies: School enrolment, Greenhouse gas emissions and Energy consumption)

and openness. Based on this, we introduce Integrated Sustainability in which sustainability spillover effect is considered as the 4th pillar to the traditional sustainable development pillars (including social, environment and economy). This perspective has the capacity to resolve both the environmental and economic issues in the two regions. Integrated Sustainability, implicitly, claims that policy-makers should follow flow-based governance, ${ }^{4}$ establish international unions and agreements and boost the global peace and partnership to foster globalization and openness which can play a key role in global sustainability.

However, the COVID-19 pandemic in 2019 reveals that the globalization process has some shortcomings, needing modifications to its current mode. The globalization of the 20th and early twenty-first century helped this disease spread rapidly and widely via the integrated global trade and tourism. In that respect, these limitations might not be the intrinsic character of globalization, but they make transitory perturbations flourish easier especially in shorter timeframe. A subsequent research can study the trends and qualities of spillover effects after the pandemic to show how this shock changed these synergetic effects. It paves the way for modifying, improving, and optimizing the mode of globalization and openness process. In addition, the other researchers can investigate these relationships among the other regions and countries providing further insight into the degree to which globalization and partnership is effective in global sustainability. While attempting to do so, other alternative proxies for the pillars of sustainable development can be adopted to check how much the claims made in this study are reliable.

\footnotetext{
${ }^{4}$ Rather than place-based governance.
} 


\section{Appendix}

See Figs. 4 and 5

East Asia \& Pacific (Asia)

to

North America
North America

to

East Asia \& Pacific (Asia)
Response to Cholesky One S.D. (d.f. adjusted) Innovations Response of CO_ASIA to Innovations

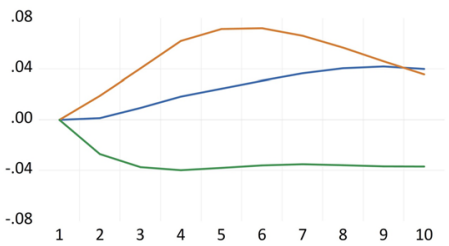

$$
\begin{aligned}
& \text { CO_NORTHAMERICA } \\
& \text { GDP_NORTHAMERICA } \\
& \text { LE_NORTHAMERICA }
\end{aligned}
$$

Response of GDP_ASIA to Innovations

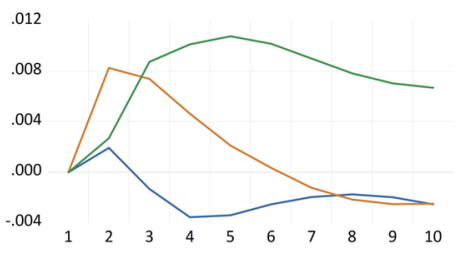

- CO_NORTHAMERICA

- GDP_NORTHAMERICA

Response of LE_ASIA to Innovations

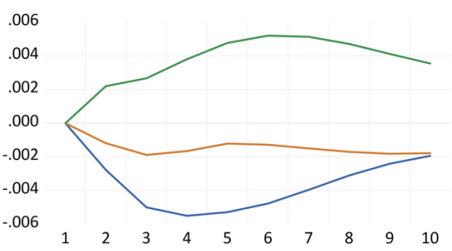

$$
\begin{aligned}
& - \text { CO_NORTHAMERICA } \\
& - \text { GDP_NORTHAMERICA } \\
& \text { LE_NORTHAMERICA }
\end{aligned}
$$

Response to Cholesky One S.D. (d.f. adjusted) Innovations

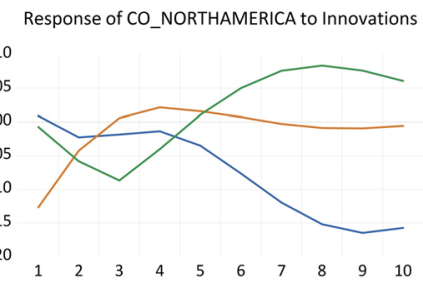

$$
\text { - CO_ASIA }
$$

Response of GDP_NORTHAMERICA to Innovations

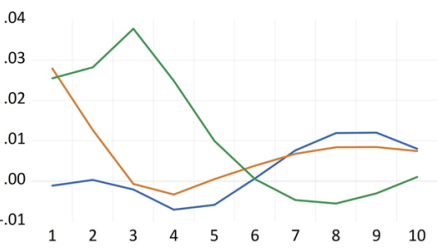

- CO_ASIA

GDP_ASIA

Response of LE_NORTHAMERICA to Innovations

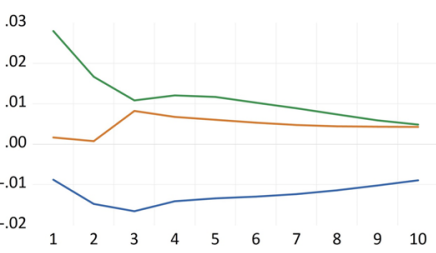

- CO_ASIA

- GDP_ASIA

LE_ASIA

Fig. 4 Impulse functions of sustainable development pillars among the two regions (CO: inverse of per capita CO2 emissions; GDP: per capita GDP; LE; life expectancy) 


\section{North America}

to

itself

Response to Cholesky One S.D. (d.f. adjusted) Innovations Response of CO_NORTHAMERICA to Innovations

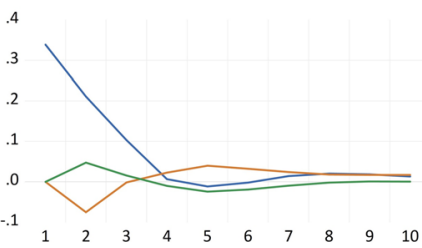

$$
\begin{aligned}
& - \text { CO_NORTHAMERICA } \\
& - \text { GDP_NORTHAMERICA } \\
& \text { LE_NORTHAMERICA }
\end{aligned}
$$

Response of GDP NORTHAMERICA to Innovations

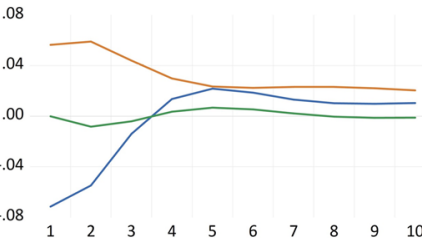

$$
\text { _ CO_NORTHAMERICA }
$$

Response of LE_NORTHAMERICA to Innovations

$$
.05
$$$$
04
$$$$
.03
$$

.02

.01

.00

$-.01$

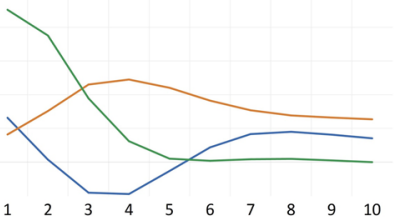

- CO_NORTHAMERICA

- GDP_NORTHAMERICA

LE_NORTHAMERICA

\section{East Asia \& Pacific (Asia)}

to

itself
Response to Cholesky One S.D. (d.f. adjusted) Innovations

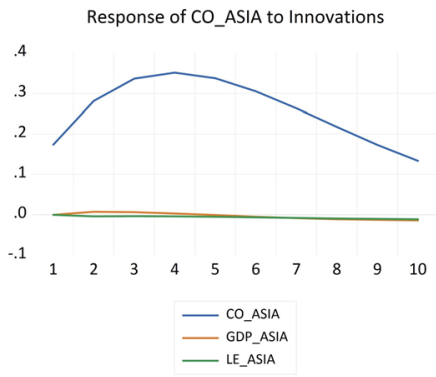

Response of GDP_ASIA to Innovations

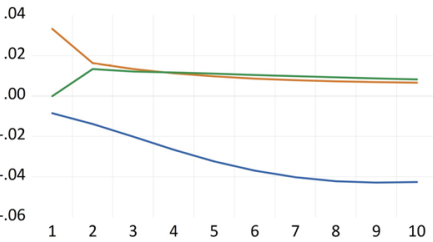

- CO_ASIA

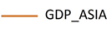

LE_ASIA

Response of LE_ASIA to Innovations

.02

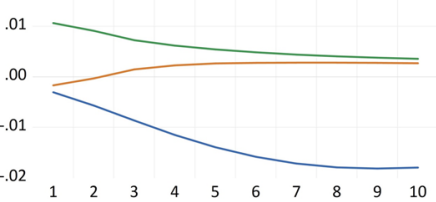

- CO_ASIA

- GDP_ASIA

Fig. 5 Impulse functions of sustainable development pillars within the two regions (CO: inverse of per capita CO2 emissions; GDP: per capita GDP; LE; life expectancy)

See Tables 4, 5, 6, 7, 8 and 9 


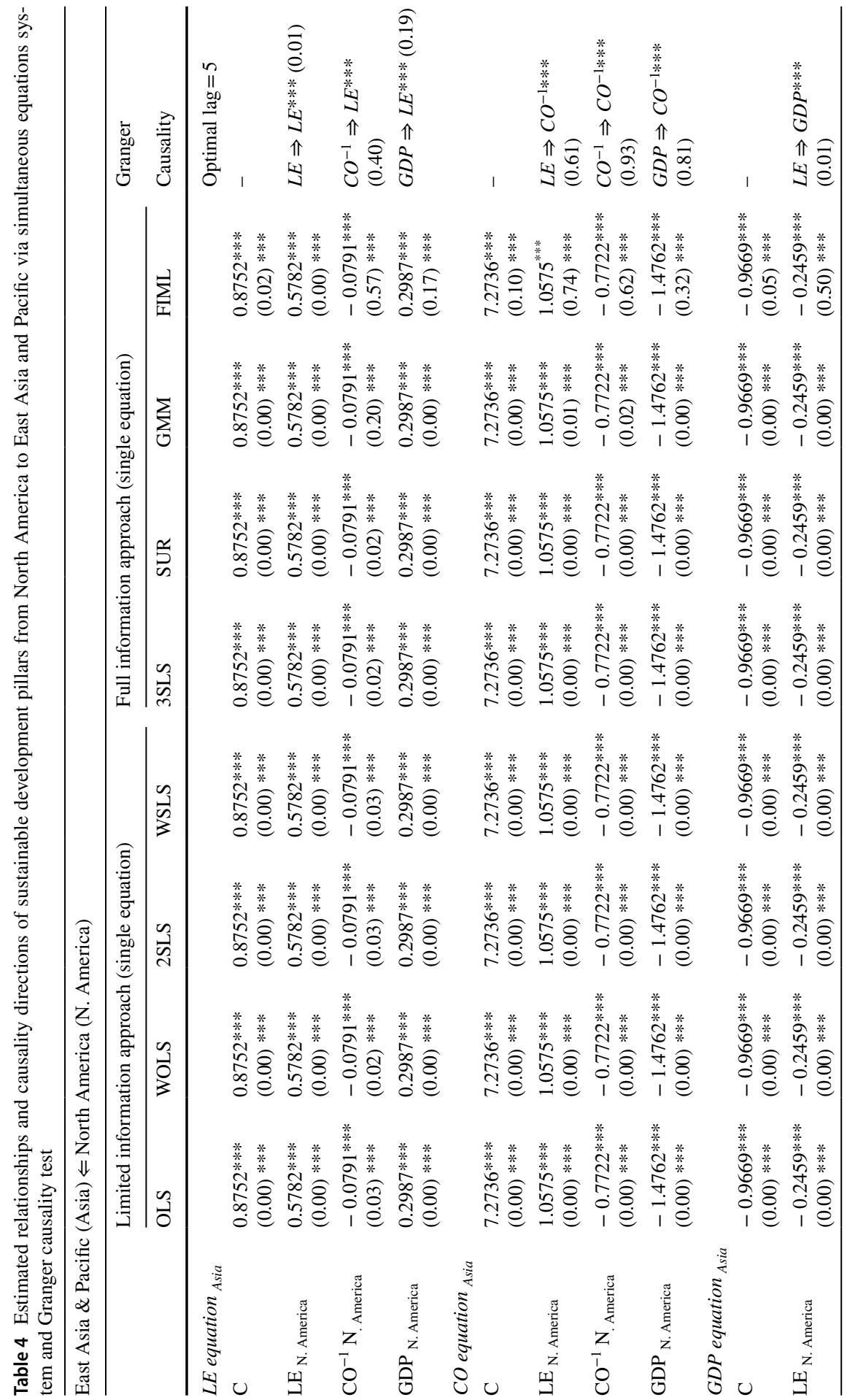




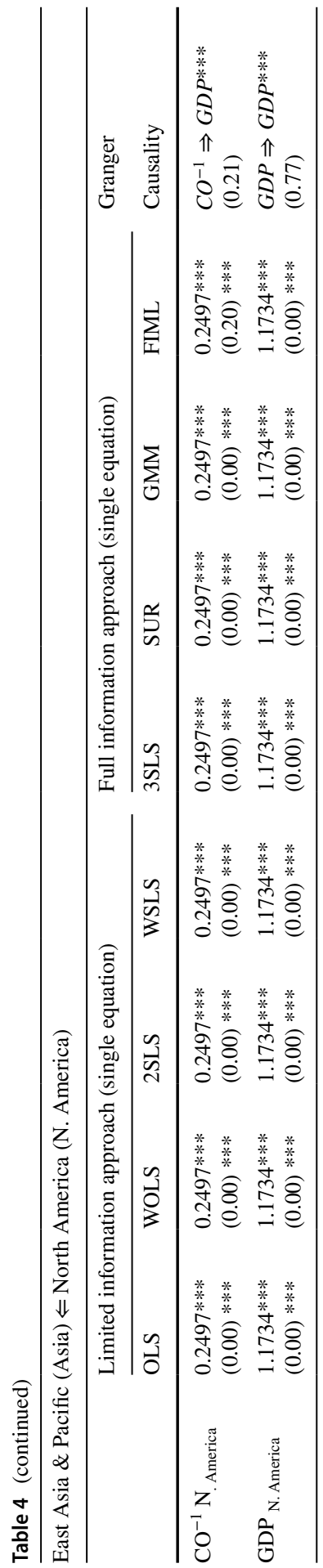




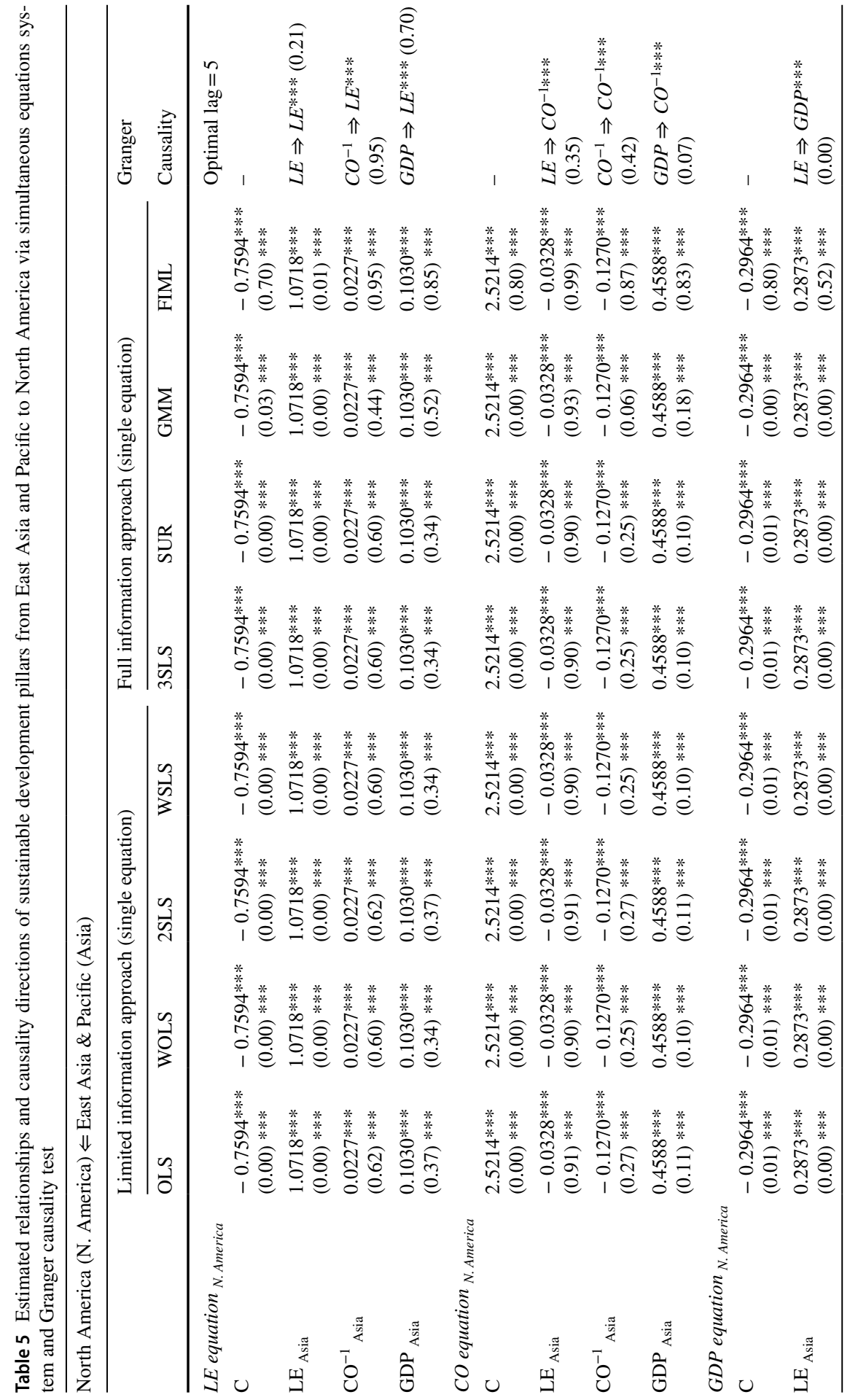




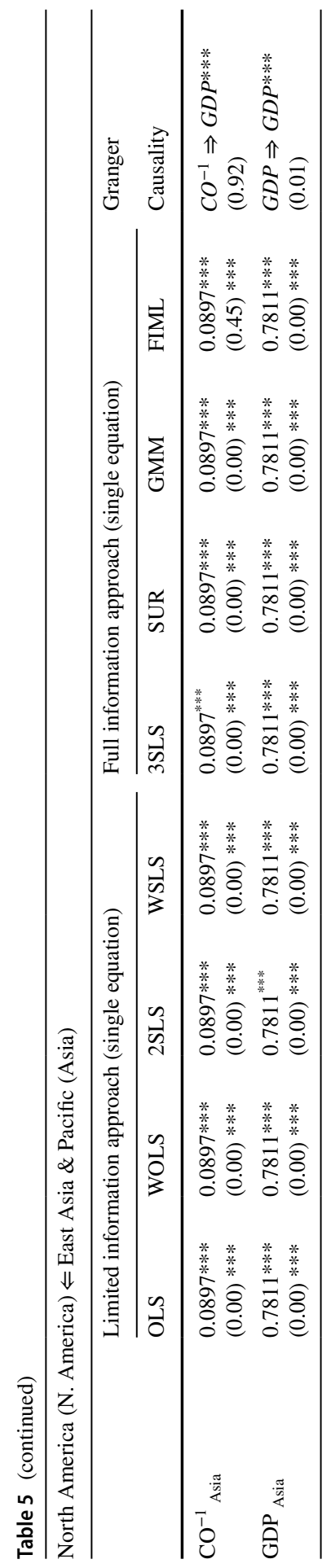




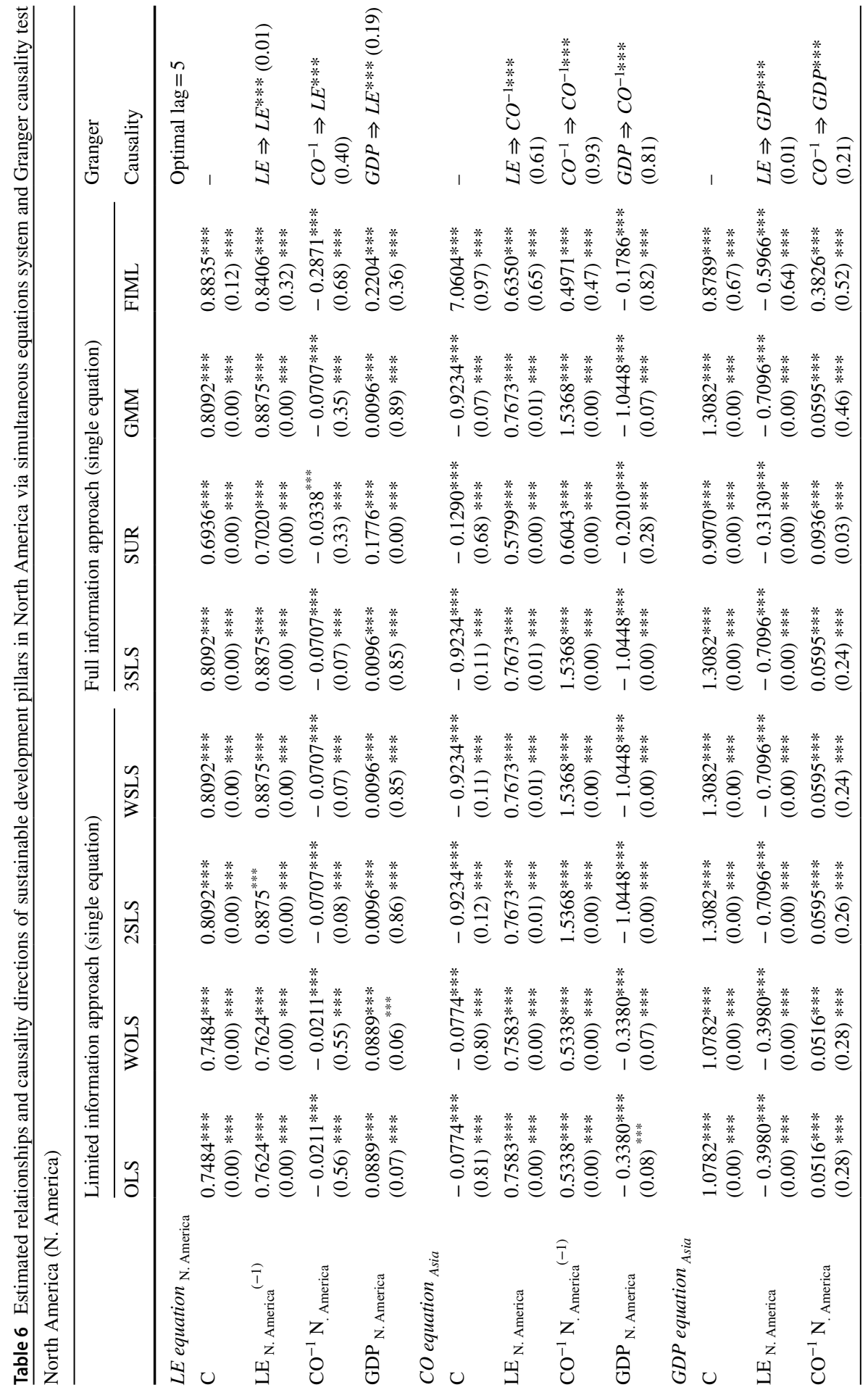




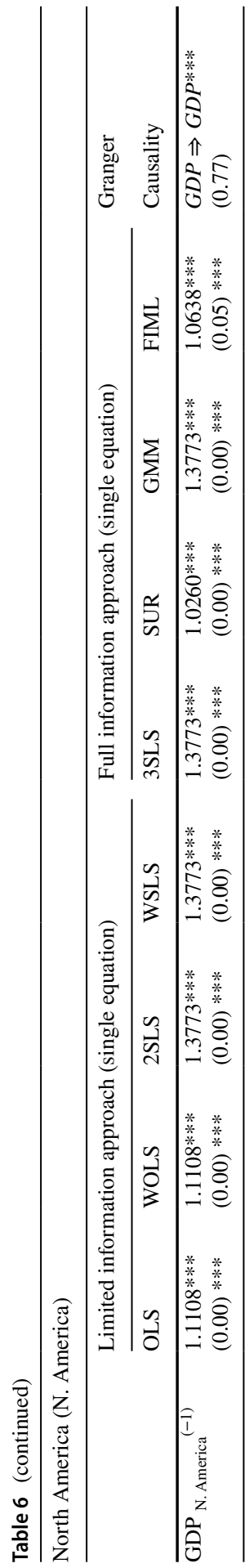




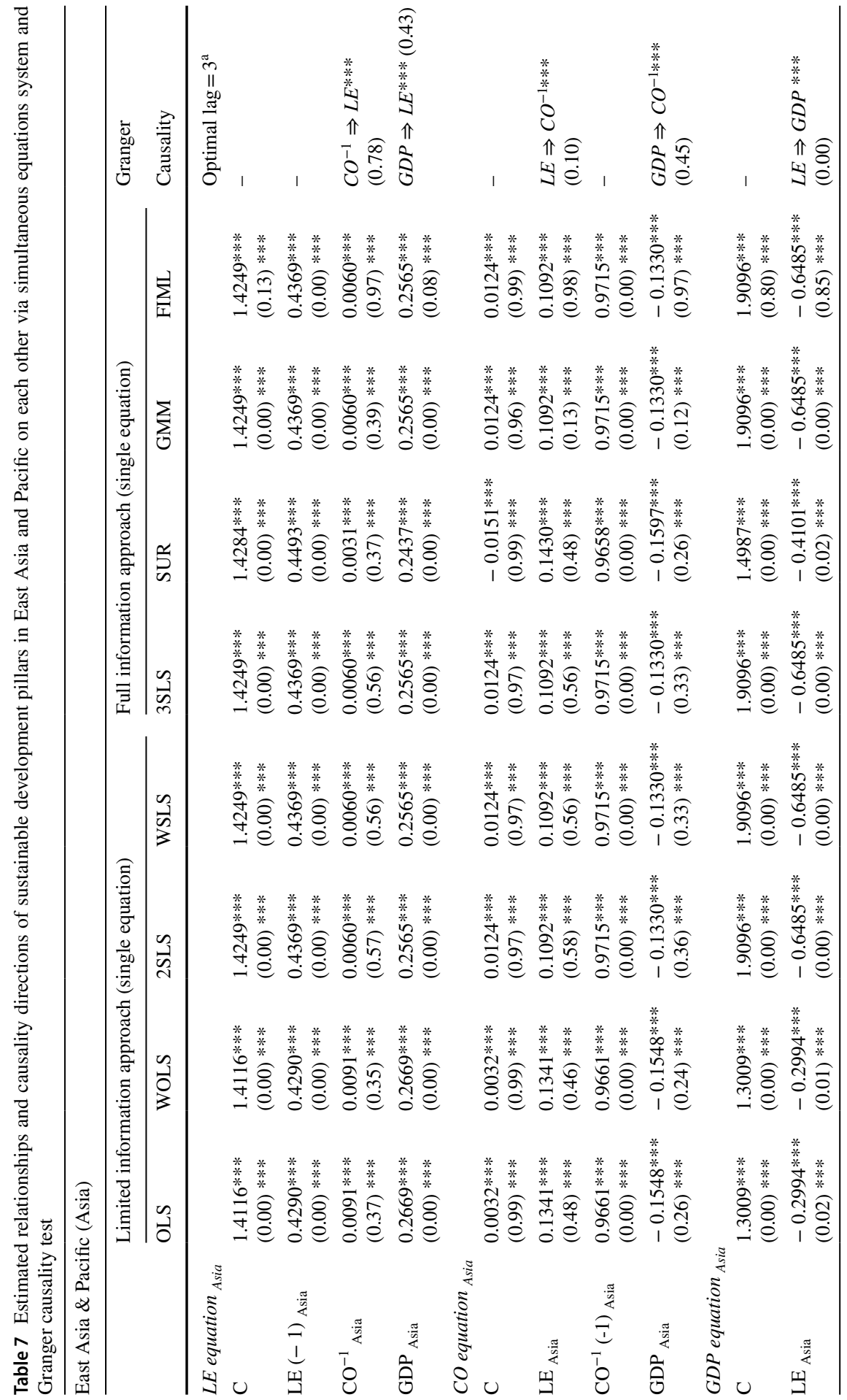




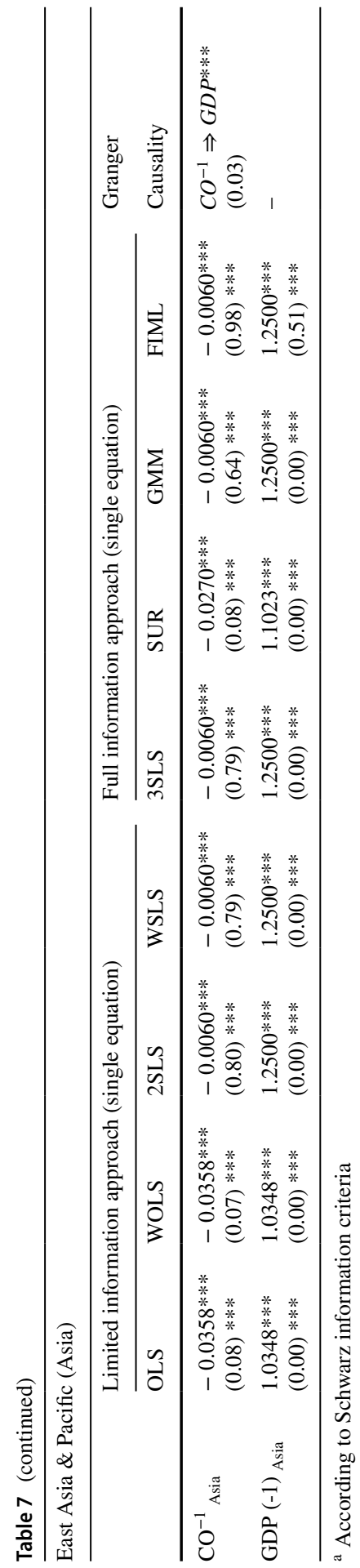




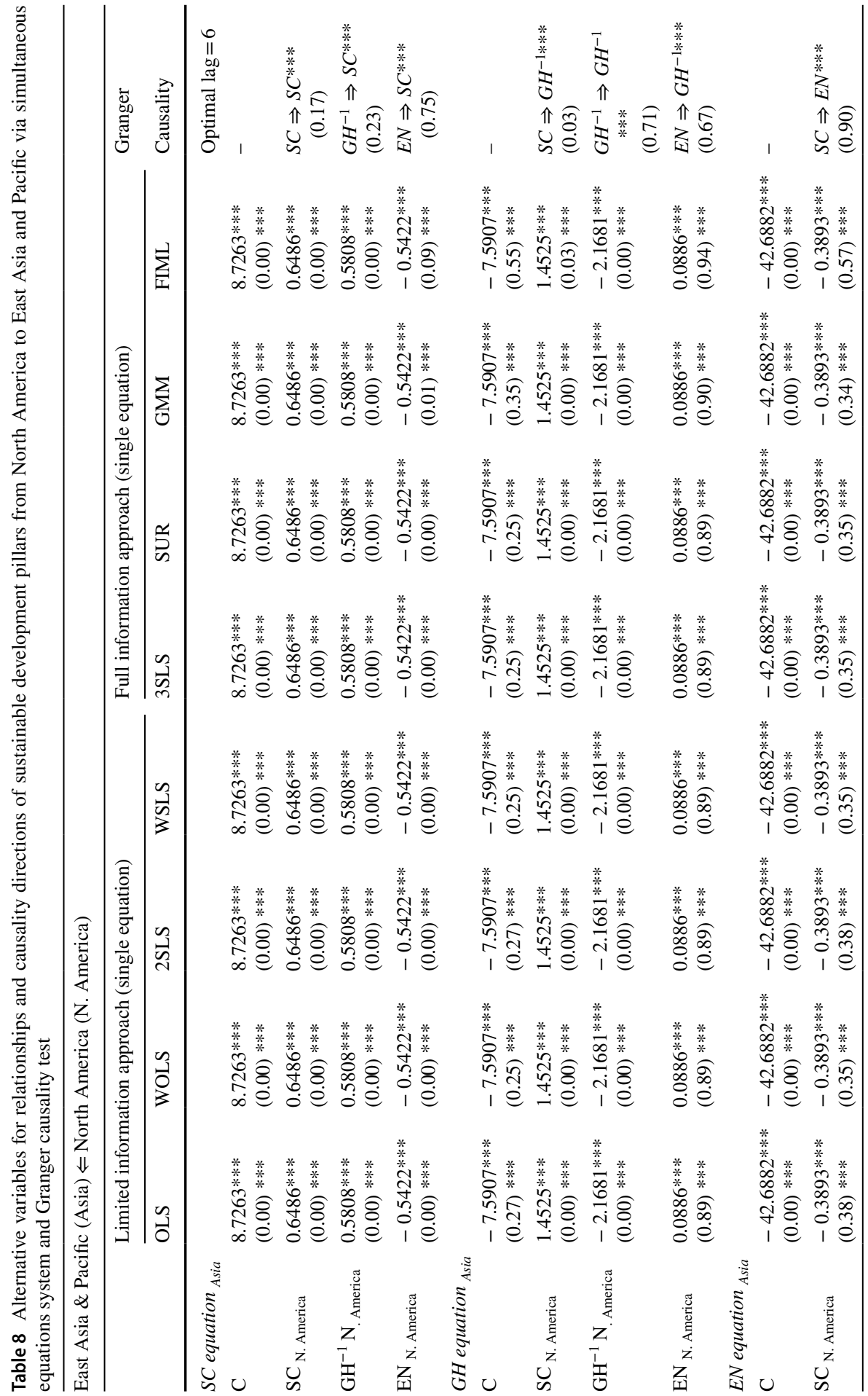




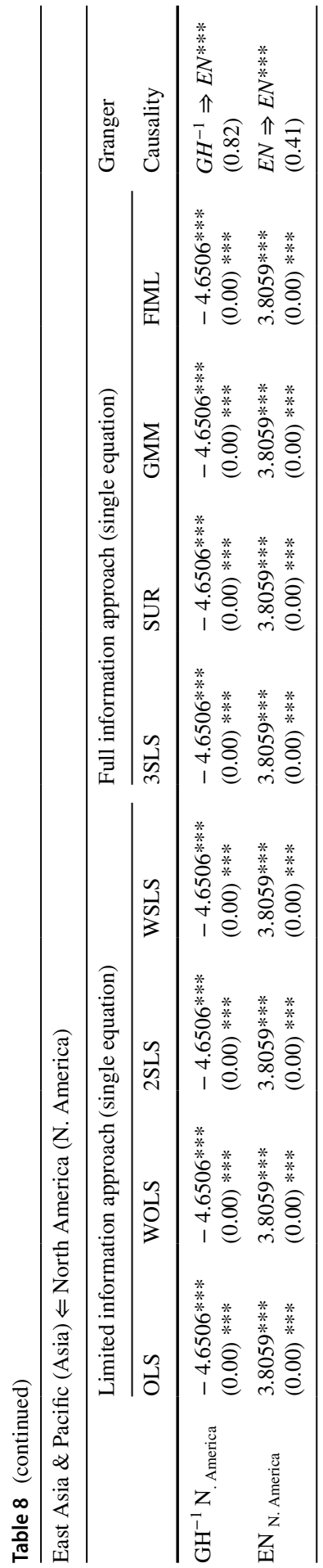




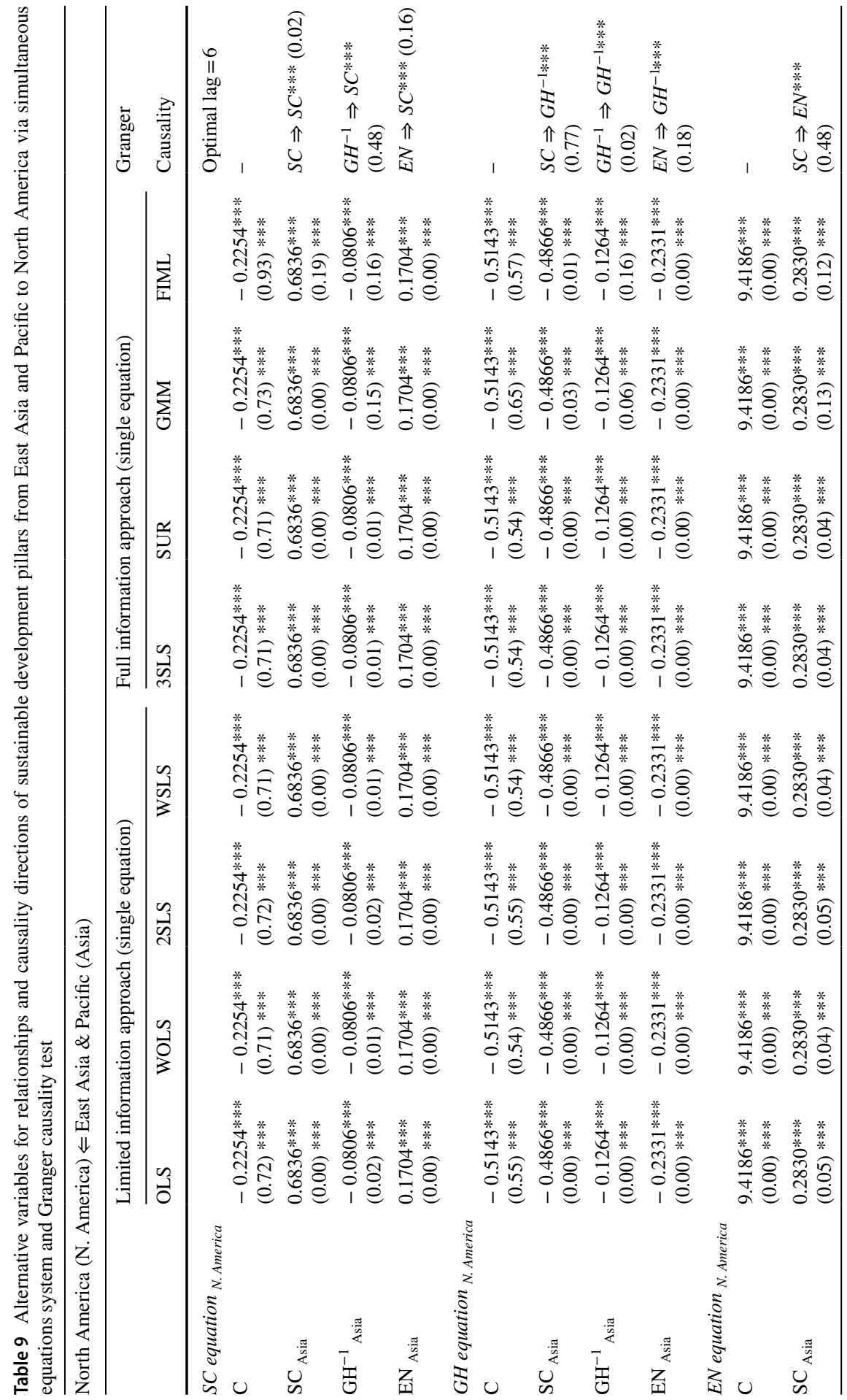




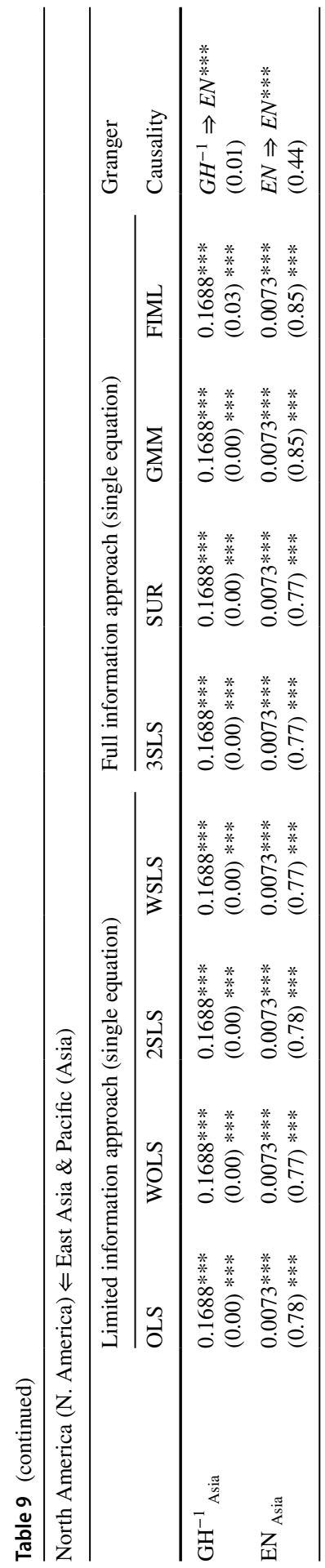


Funding No funding was received for conducting this study.

Data availability The data and the software files employed in this study are in the following link (Nodehi and Taghvaee 2021a, b). https://data.mendeley.com/datasets/xvd7bv6mjb/5

Code availability The work file of EViews software is available at the following link https://data.mende ley.com/datasets/xvd7bv6mjb/5

\section{Declarations}

Conflicts of interest The authors declare that they have no conflict of interest.

\section{References}

Abdouli, M., Omri, A.: Exploring the Nexus among FDI inflows, environmental quality, human capital, and economic growth in the mediterranean region. J. Knowl. Econ. (2020). https://doi.org/10.1007/ s13132-020-00641-5

Allen, C., Metternicht, G., Wiedmann, T.: Prioritising SDG targets: assessing baselines, gaps and interlinkages. Sustain. Sci. 14(2), 421-438 (2019). https://doi.org/10.1007/s11625-018-0596-8

Amin, A., Dogan, E., Khan, Z.: The impacts of different proxies for financialization on carbon emissions in top-ten emitter countries. Sci. Total Environ. 740, 140127 (2020). https://doi.org/10.1016/j.scito tenv.2020.140127

Basile, R.: Regional economic growth in Europe: a semiparametric spatial dependence approach. Pap. Reg. Sci. 87(4), 527-544 (2008). https://doi.org/10.1111/j.1435-5957.2008.00175.x

Basile, R., Capello, R., Caragliu, A.: Interregional knowledge spillovers and economic growth: the role of relational proximity. Adv. Spat. Sci. 68, 21-43 (2011). https://doi.org/10.1007/978-3-642-17940-2_2

Batabyal, A.A., Folmer, H.: Spatial economic aspects of climate change. Spat. Econ. Anal. 15(3), 209218 (2020). https://doi.org/10.1080/17421772.2020.1788221

Batabyal, A.A., Nijkamp, P. (eds.): Regional Growth and Sustainable Development in Asia. Springer, Newyork (2017)

Ben Youssef, A., Hammoudeh, S., Omri, A.: Simultaneity modeling analysis of the environmental Kuznets curve hypothesis. Energy Econ. 60, 266-274 (2016). https://doi.org/10.1016/j.eneco.2016. 10.005

Boutabba, M.A., Ahmad, N.: On the economic determinants of biofuel consumption: an empirical analysis for OECD countries. Int. J. Global Energy Issues 40(6), 400-418 (2017). https://doi.org/10.1504/ IJGEI.2017.089612

Brown, B.J., Hanson, M.E., Liverman, D.M., Merideth, R.W.: Global sustainability: toward definition. Environ. Manage. 11(6), 713-719 (1987). https://doi.org/10.1007/BF01867238

Fullman, N., Barber, R.M., Abajobir, A.A., Abate, K.H., Abbafati, C., Abbas, K.M., Abd-Allah, F., Abdulle, A.M., Abera, S.F., Aboyans, V., Abu-Raddad, L.J., Abu-Rmeileh, N.M.E., Adedeji, I.A., Adetokunboh, O., Afshin, A., Agrawal, A., Agrawal, S., Kiadaliri, A.A., Ahmadieh, H., Murray, C.J.L.: Measuring progress and projecting attainment on the basis of past trends of the health-related Sustainable development goals in 188 countries: an analysis from the global burden of disease study 2016. The Lancet 390(10100), 1423-1459 (2017). https://doi.org/10.1016/S0140-6736(17)32336-X

Geoffrey, J.: Advances in Spatial Science. Springer, Newyork (2007)

Hák, T., Janoušková, S., Moldan, B.: Sustainable development goals: a need for relevant indicators. Ecol. Ind. 60, 565-573 (2016). https://doi.org/10.1016/j.ecolind.2015.08.003

Hull, V., Liu, J.: Telecoupling: a new frontier for global sustainability. Ecol. Soc. (2018). https://doi.org/ 10.5751/ES-10494-230441

Ismael, M., Srouji, F., Boutabba, M.A.: Agricultural technologies and carbon emissions: evidence from Jordanian economy. Environ. Sci. Pollut. Res. 25(11), 10867-10877 (2018). https://doi.org/10.1007/ s11356-018-1327-5

Kahouli, B., Omri, A.: Foreign direct investment, foreign trade and environment: New evidence from simultaneous-equation system of gravity models. Res. Int. Bus. Financ. 42, 353-364 (2017). https:// doi.org/10.1016/j.ribaf.2017.07.161 
Liu, J., Dou, Y., Batistella, M., Challies, E., Connor, T., Friis, C., Millington, J. DA, Parish, E., Romulo, C. L., Silva, R. F. B., Triezenberg, H., Yang, H., Zhao, Z., Zimmerer, K. S., Huettmann, F., Treglia, M. L., Basher, Z., Chung, M. G., Herzberger, A., Sun, J.: Spillover systems in a telecoupled Anthropocene: typology, methods, and governance for global sustainability. In Current Opinion in Environmental Sustainability Vol. 33, pp. 58-69. Elsevier B.V (2018)

Liu, J., Mooney, H., Hull, V., Davis, S.J., Gaskell, J., Hertel, T., Lubchenco, J., Seto, K.C., Gleick, P., Kremen, C., Li, S.: Systems integration for global sustainability. Science (2015). https://doi.org/10. 1126/science. 1258832

Liu, L.J., Creutzig, F., Yao, Y.F., Wei, Y.M., Liang, Q.M.: Environmental and economic impacts of trade barriers: the example of China-US trade friction. Res. Energy Econ. 59, 101144 (2020). https://doi. org/10.1016/j.reseneeco.2019.101144

Lyytimäki, J., Salo, H., Lepenies, R., Büttner, L., Mustajoki, J.: Risks of producing and using indicators of sustainable development goals. Sustain. Dev. 28(6), 1528-1538 (2020). https://doi.org/10.1002/ sd. 2102

Mamipour, S., Yahoo, M., Jalalvandi, S.: An empirical analysis of the relationship between the environment, economy, and society: Results of a PCA-VAR model for Iran. Ecol. Ind. 102, 760-769 (2019). https://doi.org/10.1016/j.ecolind.2019.03.039

Mirshojaeian Hosseini, H., Kaneko, S.: Causality between pillars of sustainable development: global stylized facts or regional phenomena? Ecol. Ind. 14(1), 197-201 (2012). https://doi.org/10.1016/j.ecoli nd.2011.07.005

Nilsson, M., Griggs, D., Visbeck, M., Ringler, C.:A draft framework for understanding SDG interactions June 2016.

Nodehi, M., Taghvaee, V. M.: Alkali-activated materials and geopolymer: a review of common precursors and activators addressing circular economy. Circular Econ. Sustain. (2021a). https://doi.org/10. 1007/s43615-021-00029-w

Nodehi, M., Taghvaee, V.M.: Sustainable concrete for circular economy: a review on use of waste glass. Glass Struct. Eng. (2021b). https://doi.org/10.1007/s40940-021-00155-9

Nodehi, M., Taghvaee, V. M., Arani, A.A.:Data and methodology for estimating sustainability spillover effects between two regions. Mendeley Dataset (2021). https://doi.org/10.17632/xvd7bv6mjb.5

Sadorsky, P.: Asset return and volatility spillovers between big commodity producing Countries. In Emerging Markets and the Global Economy: A Handbook. Elsevier Inc. (2014). https://doi.org/10. 17632/xvd7bv6mjb.3

Smith, M.S., Cook, C., Sokona, Y., Elmqvist, T., Fukushi, K., Broadgate, W., Jarzebski, M.P.: Advancing sustainability science for the SDGs. Sustain. Sci. 13(6), 1483-1487 (2018). https://doi.org/10.1007/ s11625-018-0645-3

Štreimikienè, D., Kačerauskas, T.: The creative economy and sustainable development: The Baltic States. Sustain. Dev. 28(6), 1632-1641 (2020). https://doi.org/10.1002/sd.2111

Taghavee, V.M., Seifi Aloo, A., Shirazi, J.K.: Energy, environment, and economy interactions in Iran with. Proc. Econ. Finance 36, 414-424 (2016). https://doi.org/10.1016/S2212-5671(16)30056-9

Taghvaee, V.M., Agheli, L., Assari Arani, A., Nodehi, M., Shirazi, J.K.: Environmental pollution and economic growth elasticities of maritime and air transportations in Iran. Marine Econ. Manag. 2(2), 114-123 (2019). https://doi.org/10.1108/MAEM-09-2019-0008

Taghvaee, V. M., Arani, A. A., Nodehi, M., Shirazi, J. K., Agheli, L., Neshat Ghojogh, H. M., Salehnia, N., Mirzaee, A., Taheri, S., Mohammadi Saber, R., Faramarzi, H., Alvandi, R., Ahmadi Rahbarian, H.:Sustainable development goals: transportation, health and public policy. Rev. Econ. Polit. Sci. (2021). https://doi.org/10.1108/REPS-12-2019-0168

Taghvaee, V.M., Arani, A.A., Soretz, S., Agheli, L.: Sustainable development spillover effects in MENA and Europe: regional interactions of social, environment, and economy. Iran. Econ. Rev. (2021). https://doi.org/10.22059/IER.2021.83906

Tan, F., Lu, Z.: Study on the interaction and relation of society, economy and environment based on PCAVAR model: As a case study of the Bohai Rim region, China. Ecol. Ind. 48, 31-40 (2015). https:// doi.org/10.1016/j.ecolind.2014.07.036

Tremblay, D., Fortier, F., Boucher, J.F., Riffon, O., Villeneuve, C.: Sustainable development goal interactions: An analysis based on the five pillars of the 2030 agenda. Sustain. Dev. 28(6), 1584-1596 (2020). https://doi.org/10.1002/sd.2107

Umar, M., Ji, X., Kirikkaleli, D., Shahbaz, M., Zhou, X.: Environmental cost of natural resources utilization and economic growth: can China shift some burden through globalization for sustainable development? Sustain. Dev. 28(6), 1678-1688 (2020). https://doi.org/10.1002/sd.2116 
Uyar, A., Kuzey, C., Kilic, M.: Testing the spillover effects of sustainability reporting: evidence from the public sector. Int. J. Public Adm. 44(3), 231-240 (2021). https://doi.org/10.1080/01900692.2019. 1677711

Wang, C.C., Wu, A.: Geographical FDI knowledge spillover and innovation of indigenous firms in China. Int. Bus. Rev. 25(4), 895-906 (2016). https://doi.org/10.1016/j.ibusrev.2015.12.004

WHO.: WHO Webside. World Health Organization (WHO) (2018). http://www.who.int/airpollution/en/

World Bank.: No title. World development indicator (2021). https://databank.worldbank.org/source/ world-development-indicators

World Bank Group.:World Bank Group - International Development, Poverty, and Sustainability (2021)

Xiong, Y., Wu, S.: Real economic benefits and environmental costs accounting of China-US trade. J. Environ. Manage. 279, 111390 (2021). https://doi.org/10.1016/j.jenvman.2020.111390

Xu, Z., Li, Y., Chau, S.N., Dietz, T., Li, C., Wan, L., Zhang, J., Zhang, L., Li, Y., Chung, M.G., Liu, J.: Impacts of international trade on global sustainable development. Nat. Sustain. 3, 964-971 (2020). https://doi.org/10.1038/s41893-020-0572-z

Publisher's Note Springer Nature remains neutral with regard to jurisdictional claims in published maps and institutional affiliations.

\section{Authors and Affiliations}

\section{Mehrab Nodehi $^{1} \cdot$ Abbas Assari Arani $^{2} \cdot$ Vahid Mohamad Taghvaee $^{2}$ (D)}

Mehrab Nodehi

M_n224@txstate.edu

Abbas Assari Arani

ASSARI_A@modares.ac.ir

1 Ingram School of Engineering, Texas State University, San Marcos, TX 78666, USA

2 Department of Economic Development and Planning, Faculty of Management and Economics, Tarbiat Modares University, Tehran, Iran 